\title{
Avaliação do resíduo Cinza da Madeira de Eucalipto como substituição parcial da areia em argamassas de cimento.
}

Evaluation of Eucalyptus wood ash as partial replacement of sand in cement mortars.

Evaluación del residuo Gris de la Madera de Eucalipto como sustitución parcial de la arena en morteros de cemento.

Marcelo Bortoletto Engenheiro Civil, UNIFAI, Brasil. marcelobortoletto05@gmail.com

Paulo Victor Campos Guimarães Mestrando em Engenharia Civil, FEIS/UNESP, Brasil. paulovictorcamposg@gmail.com

Rodrigo Garozi da Silva Mestrando em Engenharia Civil, FEIS/UNESP, Brasil. garozirodrigo@gmail.com

Jorge Luís Akasaki Livre Docente, FEIS/UNESP, Brasil. jorge.akasaki@gmail.com 


\section{RESUMO}

$\mathrm{O}$ uso de materiais suplementares em concretos e argamassas de cimento Portland vem se tornando crescente devido aos danos ambientais que a produção de cimento e a extração de agregados naturais podem causar ao meio ambiente. $\mathrm{O}$ objetivo deste artigo é avaliar a eficiência da cinza de madeira de eucalipto (CME) como substituto parcial do agregado miúdo em argamassas de cimento Portland, almejando reduzir a quantidade de agregados naturais e dar uma destinação correta à um resíduo industrial. Para isso foram fabricados corpos de prova (CPs) de argamassas com substituição de $0 \%$ (controle), 10\%, 20\%, 30\%, 40\% e 50\% de CME pelo agregado miúdo, mantendo constante em todos os traços a quantidade de cimento e água/cimento (a/c). Os CPs foram ensaiados à compressão axial, à consistência e à absorção de água. Observou-se um acréscimo na resistência à compressão axial, comparando-se ao controle, com o aumento da porcentagem de substituição até $30 \%$ de $\mathrm{CME}$, enquanto que a fluidez diminuiu com o aumento de CME em todas as amostras, diminuindo a trabalhabilidade. Da mesma forma, a absorção de água diminui com o aumento de CME nas misturas, melhorando a compacidade das misturas. Pode-se concluir com base nos resultados apresentados que o uso de CME até $30 \%$ em substituição ao agregado miúdo é interessante, sendo esta a porcentagem ideal, pois agrega os melhores resultados de resistência à compressão das argamassas, com trabalhabilidade aceitável e redução da absorção de água. A utilização desse material também colabora para a redução dos danos ambientais.

PALAVRAS-CHAVE: Danos ambientais. Materiais suplementares. Cinza de madeira de eucalipto.

\section{ABSTRACT}

The use of supplementary materials in Portland cement concrete and mortars has been increasing due to the environmental damages that the cement production and the extraction of natural aggregates can cause to the environmental. The goal of this paper is evaluate the efficiency of Eucalyptus wood ash (EWA) as partial replacement of fine aggregates in Portland cement mortars, aiming to reduce the amount of natural aggregates and to give a correct destination to an industrial waste. For this purpose mortar specimens (MSs) were replaced with $0 \%$ (control), $10 \%, 20 \%, 30 \%, 40 \%$ and $50 \%$ of EWA by the fine aggregate, maintaining constant in all mixes the amount of cement and water / cement ( $\mathrm{w} / \mathrm{c}$ ). The MSs were tested for axial compression, flowing and water absorption. An increase in the axial compressive strength was observed, comparing to the control, with the percentage of substitution increasing up to $30 \% \mathrm{CME}$, whereas the flowing decreased with the increase of the EWA in all the samples, reducing the workability. Likewise, the water absorption decreases with the increase of EWA in mistures, improving the compactness of the mixtures. It can be concluded from the results presented that the use of EWA up to $30 \%$ in replacement to the fine aggregate is interesting, being it the ideal percentage, because it aggregates the best results of compressive strength of mortars, with acceptable workability and reduction of water absorption. The use of this material also contributes to the reduction of environmental damage.

KEYWORDS: Environmental damages. Supplementary materials. Eucalyptus wood ash.

\section{RESUMEN}

El uso de materiales suplementarios en hormigones y morteros de cemento Portland se está volviendo creciente debido a los daños ambientales que la producción de cemento y la extracción de agregados naturales pueden causar al medio ambiente. El objetivo de este artículo es evaluar la eficiencia de la gris de madera de eucalipto (CME) como sustituto parcial del agregado en los morteros de cemento de Portland, buscando reducir la cantidad de agregados naturales y dar un destino adecuado a un residuo industrial. Para ello se fabricaron cuerpos de prueba de morteros con sustitución de $0 \%$ (control), 10\%, 20\%, 30\%, 40\% y 50\% de CME por el hogar, manteniendo constante en todos los trazos la cantidad de cemento y agua / cemento (a / c). Los CP se sometieron a la compresión axial, a la consistencia ya la absorción de agua. Se observó un aumento en la resistencia a la compresión axial, comparándose con el control, con el aumento del porcentaje de sustitución hasta $30 \%$ de CME, mientras que la fluidez disminuyó con el aumento de CME en todas las muestras, disminuyendo la trabajabilidad. De la misma forma, la absorción de agua disminuye con el aumento de CME en las mezclas, mejorando la compacidad de las mezclas. Se puede concluir con base en los resultados presentados que el uso de CME hasta un $30 \%$ en sustitución del agregado es interesante, siendo éste el porcentaje ideal, pues agrega los mejores resultados de resistencia a la compresión de los morteros, con la asequibilidad aceptable y la reducción de la absorción de agua. La utilización de este material también colabora para reducir los daños ambientales.

PALABRAS CLAVE: Daños ambientales. Materiales adicionales. Gris de madera de eucalipto. 


\section{ANAP Brasil \\ ISSN 1984-3240 \\ v. 10, n. 18}

\section{REVISTA C IENTÍFICA $\quad 2017$}

\section{INTRODUÇÃO}

O clínquer do cimento Portland é tradicionalmente conhecido como um dos principais aglomerantes utilizados. Porém em seu processo de fabricação, grande quantidade de dióxido de carbono é produzido, o que torna esse material um dos principais responsáveis por sua emissão global. Estima-se que para cada tonelada de cimento produzido, é emitida 1 tonelada de dióxido de carbono (FAIRBAIRN et al., 2010).

Dessa maneira é crescente a busca por materiais que possam substituir parcial ou totalmente o clínquer, como é o caso dos materiais suplementares. Esses materiais começaram a ser usados nas misturas de concretos e argamassas devido ao seu custo mais barato, a necessidade de dar-se um destino apropriado à resíduos de vários ramos industriais e também para diminuir a utilização de cimento Portland, devido ao seu potencial poluidor (NEVILLE, 2016). Além desses benefícios, os materiais suplementares podem promover uma melhor hidratação do cimento aplicado, otimizando seu desempenho, e também contribuir para o aumento de resistência mecânica e da durabilidade de matrizes cimentantes, podendo reduzir assim, a quantidade de cimento aplicado para obter concretos e argamassas de boa qualidade.

Os materiais suplementares também podem substituir os agregados em argamassas e concretos, uma vez que as questões ambientais também influenciam em sua utilização. A abertura de novas pedreiras e jazidas de exploração de agregados têm, atualmente, várias restrições, e aliado à problemas de disposição de alguns resíduos tornam a substituição de agregados naturais por agregados residuais uma alternativa interessante (NEVILLE, 2016).

O cimento CP V Ari (Alta resistência inicial - NBR 5737) é indicado para fabricação de elementos pré-moldados e obras em que se necessita de alta resistência nas primeiras idades para rápida desforma. Este material também é muito usado em testes laboratoriais, onde se almeja as máximas resistências em poucos dias. O CP V Ari possui normalmente de $95 \%$ a $100 \%$ de clínquer + gesso, possuindo normalmente uma quantidade muito pequena de outras misturas em sua composição. Os aspectos que proporcionam a alta resistência inicial desenvolvida por esse cimento são: a utilização de uma dosagem diferente de calcário e argila para a produção do clínquer, dessa forma é elevado o conteúdo de alita e $C_{3} A$; e a melhor moagem do clínquer, fazendo que esse tipo de cimento seja mais fino (KIHARA; CENTURIONE, 2005).

Ao longo de sua existência, a indústria de celulose e papel tem mostrado enorme vitalidade para crescer sua produção e aperfeiçoar suas tecnologias para atender as exigências das quantidades e qualidades requeridas em seus produtos pela sociedade (FOELKEL, 2008). Segundo Foelkel (2008), a ecoeficiência demanda a utilização eficiente dos recursos naturais que estão disponíveis. 


\section{ANAP Brasil \\ ISSN 1984-3240 \\ v. 10, n. 18}

\section{REVISTA C IENTÍFICA $\quad 2017$}

Rossi et al (2017) retrata que o Eucalipto é cultivado em inúmeros países, sendo atualmente o Brasil, a Índia e a China os líderes em produção, numa escala que ultrapassa os 20 milhões de hectares mundo a fora. Existe uma variedade de usos desse material, incluindo a submissão da lenha a $95^{\circ} \mathrm{C}$ numa câmara fechada para posterior manipulação e alcance da tonalidade avermelhada, quando é direcionado para fabricação de mobílias.

Conforme Santos et al (2017), apesar do Eucalipto ser uma planta nativa da Austrália, trata-se de um dos cultivos florestais mais difundidos, especialmente por companhias de papel e celulose, justamente pela adaptabilidade à diferentes condições climáticas, pelo rápido crescimento observado e pelas excelentes propriedades da madeira do eucalipto. Seu impacto econômico em escala mundial é, portanto, significativo. Santos et al (2017) ainda ressalta que apesar das preocupações ambientais que cercam tal espécime, a alta incidência das florestas de Eucalipto contribui para diminuir as pressões sobre as indústrias, uma vez que esse cultivo substitui naturalmente as florestas tropicais, comprometendo a biodiversidade notória destas.

As fábricas de celulose e papel são grandes geradoras de resíduos sólidos, quer seja de origem orgânica ou inorgânica (ou mineral). Essa geração tem sido proporcionalmente aumentada em função dos fechamentos de circuitos nas fábricas e a busca pela resolução dos problemas das poluições hídricas e aéreas do setor (FOEKEL, 2017). Com essas medidas, uma grande parte da poluição que antes saia na forma de poluentes aéreos (poeiras e partículas) ou de poluentes hídricos (matéria orgânica dissolvida em efluentes e partículas/fibras suspensas) tem sido desviada para a forma de resíduos sólidos. Esses são mais fáceis de serem manuseados, dispostos e gerenciados, o que favorece a ecoeficiência nas operações (FOEKEL, 2017).

Alguns números são de grande valia para se compreender a magnitude da geração de resíduos pelas indústrias de papel e celulose. Um processo comumente utilizado nesse ramo industrial é o Kraft. Esse procedimento ocorre a 150 C com adição de Sulfato de Sódio e Soda Cáustica, dissolvendo a lignina e liberando a celulose como polpa de papel de maior qualidade (CMPC CELULOSE RIOGRANDENSE, 2017). Uma fábrica de celulose Kraft com tratamento biológico a nível secundário para seus efluentes e com uma caldeira de biomassa em nível de caldeira auxiliar pode gerar entre 20 a $90 \mathrm{~kg}$ de resíduos minerais base seca por tonelada de celulose produzida e entre 10 a $30 \mathrm{~kg}$ de resíduos orgânicos base seca pela mesma tonelada de celulose (FOEKEL, 2017). As mais modernas fábricas de celulose Kraft, as de última geração tecnológica, estão mostrando gerações totais de resíduos sólidos entre 40 a $70 \mathrm{~kg}$ secos/adt de celulose (adt = air dry ton - tonelada seca ao ar). Isso corresponde, nessas modernas fábricas, a cerca de 70 a $120 \mathrm{~kg}$ nas umidades tais quais gerados por tonelada de celulose produzida (FOEKEL, 2017).

Todo resíduo industrial no Brasil precisa ter sua classificação estabelecida com base nas avaliações de composição, lixiviação, toxicologia e periculosidade. Existem diversas normas da ABNT para isso. Só a partir dessa classificação é que se podem estabelecer programas de 


\section{ANAP Brasil}

ISSN 1984-3240

v. 10, n. 18

\section{REVISTA C I E N TÍF I C A $\quad 2017$}

disposição, compostagem, reutilização, aplicação em solos agrícolas ou florestais, etc (FOEKEL, 2017). A maioria dos resíduos sólidos industriais gerados no processo de fabricação de celulose e papel são Classe IIA - Não Perigosos - Não Inertes, logo não são considerados da classe dos perigosos (FOEKEL, 2017).

A cinza da madeira de eucalipto (CME) provém tanto do fundo (cinzas de fundo) como do precipitador de coleta de particulados dos gases de exaustão da caldeira de força alimentada em base de biomassa energética (madeira e/ou casca de árvores). Pode ter cor preta intensa (devido altos teores de carbono não queimado) ou ter coloração cinza clara (como sugere o nome). A consistência é muito variada, em função das diferentes tecnologias para as caldeiras de força a base de biomassa. Podemos ter cinzas bastante secas (entre 95 a quase $100 \%$ de consistência), como cinzas úmidas (cerca de $50-60 \%$ de consistência) recolhidas por ciclones e que são molhadas com água para resfriamento. Exatamente por essas diferenças tecnológicas, a geração de cinzas varia entre 5 a $40 \mathrm{~kg}$ de cinzas absolutamente secas/adt de celulose produzida (FOEKEL, 2017).

\section{OBJETIVOS}

Avaliar a eficiência da cinza da madeira de eucalipto aplicada como substituição parcial do agregado miúdo, na produção de argamassas de cimento, visando um novo destino à um resíduo recorrente na economia nacional e oferecendo um material alternativo para funcionar como agregado, considerando a futura disponibilidade da areia natural.

\section{METODOLOGIA}

\subsection{MATERIAIS}

\subsubsection{Agregado miúdo}

O agregado miúdo utilizado na pesquisa foram a Areia Média Natural provenientes, do Porto Nossa Senhora Aparecida e Pedreira Três Irmãos, de Andradina - SP. Este foi submetido aos seguintes ensaios de caracterização, conforme a ASSOCIAÇÃO BRASILEIRA DE NORMAS TÉCNICAS (ABNT):

- $\quad$ Composição granulométrica, pela NBRNM 248 (ABNT, 2001).

- Massa específica e massa específica aparente, pela NBRNM 52 (ABNT, 2009).

- $\quad$ Absorção de água, pela NBRNM 30 (ABNT, 2001).

- $\quad$ Massa unitária, pela NBRNM 45 (ABNT, 2006).

- Massa específica e massa específica aparente, seguindo as recomendações da NBRNM 53 (ABNT, 2009). 


\section{ANAP Brasil}

ISSN 1984-3240

v. 10, n. 18

\section{REVISTA C IENTÍFICA 2017}

\subsubsection{Aglomerante}

O aglomerante escolhido foi o cimento CPV-ARI-Plus - Cimento Portland de Alta Resistência Inicial. Trata-se do cimento mais puro dentre as tipologias usadas no mercado. Seu teor de adições é mínimo comparado aos demais.

\subsubsection{Cinza da madeira de eucalipto}

A CME foi fornecida pela Fibria (empresa de celulose; unidade de Três Lagoas - SP). Seu emprego se dará em substituição parcial ao agregado miúdo. O material foi caracterizado, por meio da análise de sua composição química e física (granulometria).

\subsection{MÉTODOS}

\subsubsection{Preparo da cinza da madeira de eucalipto}

\subsubsection{Secagem}

A cinza proveniente da empresa de celulose carregava certa umidade não conveniente para o trabalho em questão. Fez-se necessário, portanto, proceder com a secagem deste material.

\subsubsection{Moagem}

Após a secagem da cinza, a etapa de moagem vem para fornecer um diâmetro final satisfatório para a aplicação do material nas argamassas. Foram utilizados 15 quilogramas do material. Utilizou-se o moinho de bolas, reservando um tempo para a moagem de 60 minutos para cada parcela de $15 \mathrm{~kg}$.

\subsubsection{Fabricação da argamassas}

\subsubsection{Definição dos traços}

No presente trabalho utilizou-se o traço 1:2 e uma relação água/cimento de 0,50 para cada amostra. A quantidade de materiais utilizados para cada amostra está descrita na tabela 1. 


\section{ANAP Brasil \\ ISSN 1984-3240 \\ v. 10 , n. 18}

\section{REVISTA C IENTÍFICA 2017}

Tabela 1- Quantidade de materiais utilizados para cada amostra

\begin{tabular}{lccccc}
\hline $\begin{array}{c}\text { Teor de substituição por } \\
\text { CME }\end{array}$ & Cimento (Kg) & Areia (Kg) & Água (Kg) & $\begin{array}{c}\text { CME } \\
(\mathbf{K g})\end{array}$ & $\begin{array}{c}\text { Quantidade } \\
(\mathbf{k g})\end{array}$ \\
\hline CME 0\% & 1,00 & 2,00 & 0,50 & 0,00 & 3,50 \\
CME 10\% & 1,00 & 1,80 & 0,50 & 0,20 & 3,50 \\
CME 20\% & 1,00 & 1,60 & 0,50 & 0,40 & 3,50 \\
CME 30\% & 1,00 & 1,40 & 0,50 & 0,60 & 3,50 \\
CME 40\% & 1,00 & 1,20 & 0,50 & 0,80 & 3,50 \\
CME 50\% & 1,00 & 1,00 & 0,50 & 1,00 & 3,50 \\
& & & & & \\
\hline
\end{tabular}

Fonte: Próprio autor.

\subsubsection{Mistura}

Procedida a pesagem dos materiais, iniciou-se o processo de mistura mecânica das argamassas. Inicialmente, foram adicionados água e o aglomerante. A argamassadeira foi ligada à $124 \mathrm{rpm}$ por 30 segundos e em seguida a $220 \mathrm{rpm}$ por mais 30 segundos. Posteriormente foi acrescentada, de maneira gradual, toda a areia/CME no tempo de 30 segundos, a $124 \mathrm{rpm}$. Em seguida a argamassa formada foi misturada por mais 60 segundos a $220 \mathrm{rpm}$. Finalizada a argamassa, dá-se continuidade ao procedimento ensaiando a consistência do material. A figura abaixo ilustra a argamassa após a mistura dos componentes.

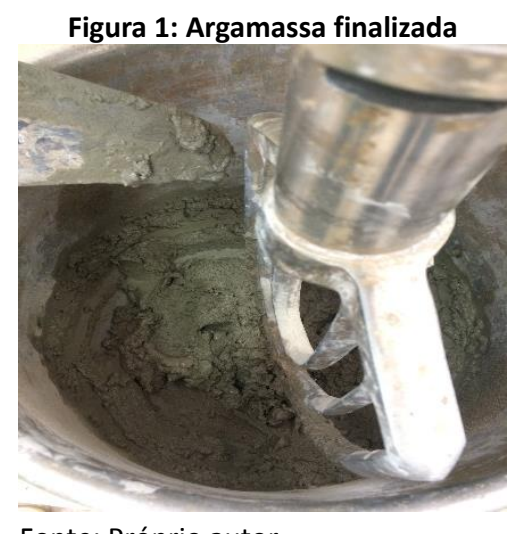

Fonte: Próprio autor.

\subsubsection{Ensaio de consistência}

Após a mistura, determinou-se a água para obtenção do Índice de Consistência (NBR 13276 ABNT, 2016). Este estudo permitiu avaliar a consistência de todos os traços por meio da utilização da mesa "flow table". A figura em sequência ilustra as etapas do ensaio: 


\section{ANAP Brasil \\ ISSN 1984-3240 \\ v. 10, n. 18}

\section{REVISTA C IENTÍF I CA 2017}

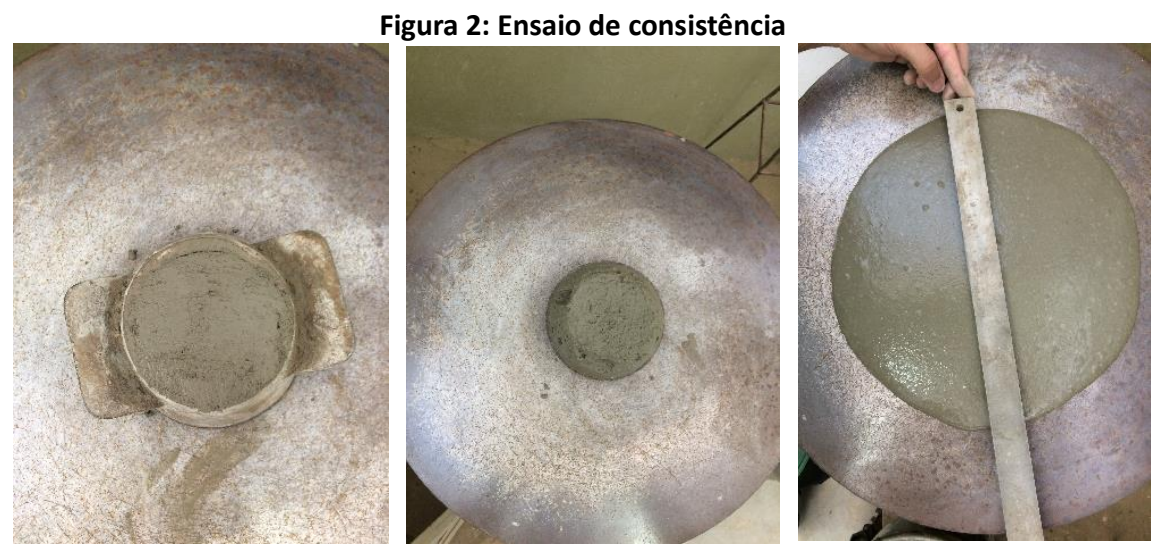

Fonte: Próprio autor.

\subsubsection{Adensamento, moldagem e cura das argamassas}

Uma mesa vibratória foi empregada na etapa de adensamento da mistura, com tempo de utilização de 60 segundos por molde. Foram utilizados moldes metálicos cúbicos com $5 \mathrm{~cm}$ de lado. Os corpos de prova confeccionados para este trabalho permaneceram em câmara úmida para cura, mediante temperatura de $28^{\circ} \mathrm{C}$ e umidade relativa do ar de $100 \%$, até a idade de ensaio.

\subsubsection{Ensaio de resistência à compressão axial}

Após o tempo de cura de cada corpo de prova, foram realizados ensaios de resistência à compressão axial (NBR 5739 - ABNT, 2007). A idade de ensaio foi estabelecida para 7 dias. 0 número de amostras foi definido em quatro por traço em estudo. Os dados de Resistência à Compressão foram calculados considerando a média das amostras e o seu respectivo desvio padrão.

\subsubsection{Ensaio de absorção de água}

Após o tempo de cura de cada corpo de prova, foram realizados ensaios de absorção (NBR 9778 - ABNT, 2009). São procedidas duas pesagens ao corpo-de-prova para avaliar o teor de água absorvido: um pesagem seca (antes da imersão em água) e após 24 horas de imersão, procede-se com a segunda pesagem (corpo-de-prova com água incorporada). 0 ensaio foi realizado para a idade de 7 dias. Os dados foram calculados mediante duas amostras e 0 resultado final advém da média aritmética desses valores. 


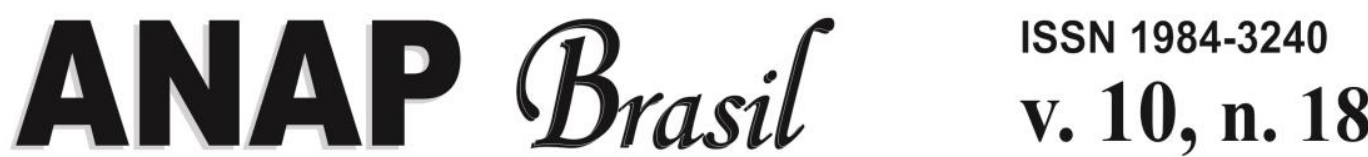

\section{REVISTA C IENTÍFICA 2017}

\section{RESULTADOS}

\subsection{Caracterização da cinza da madeira de eucalipto}

A composição química foi obtida através da espectroscopia por FRX, apresentada no Quadro 1, e possibilitou a determinação da composição dos óxidos presentes na $\mathrm{CME}$, assim como identificou a presença de carbono residual na amostra de cinza.

Quadro 1: Composição química da cinza da madeira de eucalipto (porcentagem do óxido indicado)

\begin{tabular}{|c|c|c|c|c|c|c|c|c|c|c|}
\hline $\mathbf{S i O}_{\mathbf{2}}$ & $\mathbf{A l}_{2} \mathbf{O}_{\mathbf{3}}$ & $\mathrm{Fe}_{2} \mathbf{O}_{3}$ & $\mathrm{CaO}$ & $\mathbf{N a}_{2} \mathbf{O}$ & $\mathbf{K}_{2} \mathbf{O}$ & $\mathbf{S O}_{3}$ & $\mathrm{Cl}$ & $\mathrm{TiO}_{2}$ & Outros & $\mathbf{P F}$ \\
\hline 39,2 & 9,2 & 5,8 & 25,0 & 0,6 & 5,5 & 5,6 & 1,0 & 1,9 & 6,2 & \\
\hline
\end{tabular}

Fonte: Próprio autor.

A granulometria da cinza pode ser observada na figura abaixo, com a indicação das curvas discreta e acumulada. Considerando o tempo de moagem de 60 minutos, o diâmetro médio das partículas foi definido em $45 \mu \mathrm{m}$.

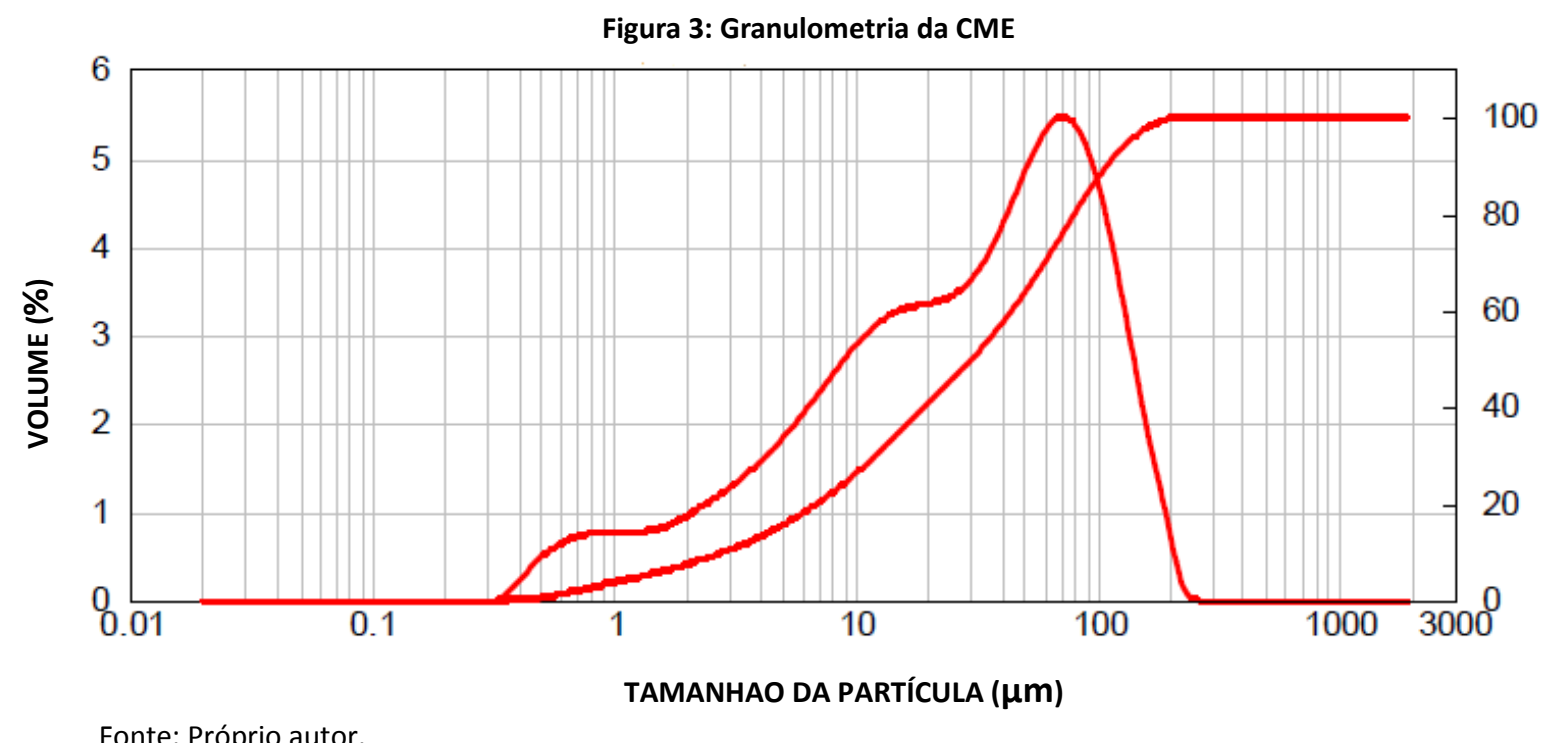

\subsection{Caracterização da areia}

Conforme os ensaios mencionados na metodologia, seguem os dados característicos da areia utilizada: 


\section{ANAP Brasil \\ ISSN 1984-3240 \\ v. 10, n. 18}

REVISTA CIENTÍFICA

2017

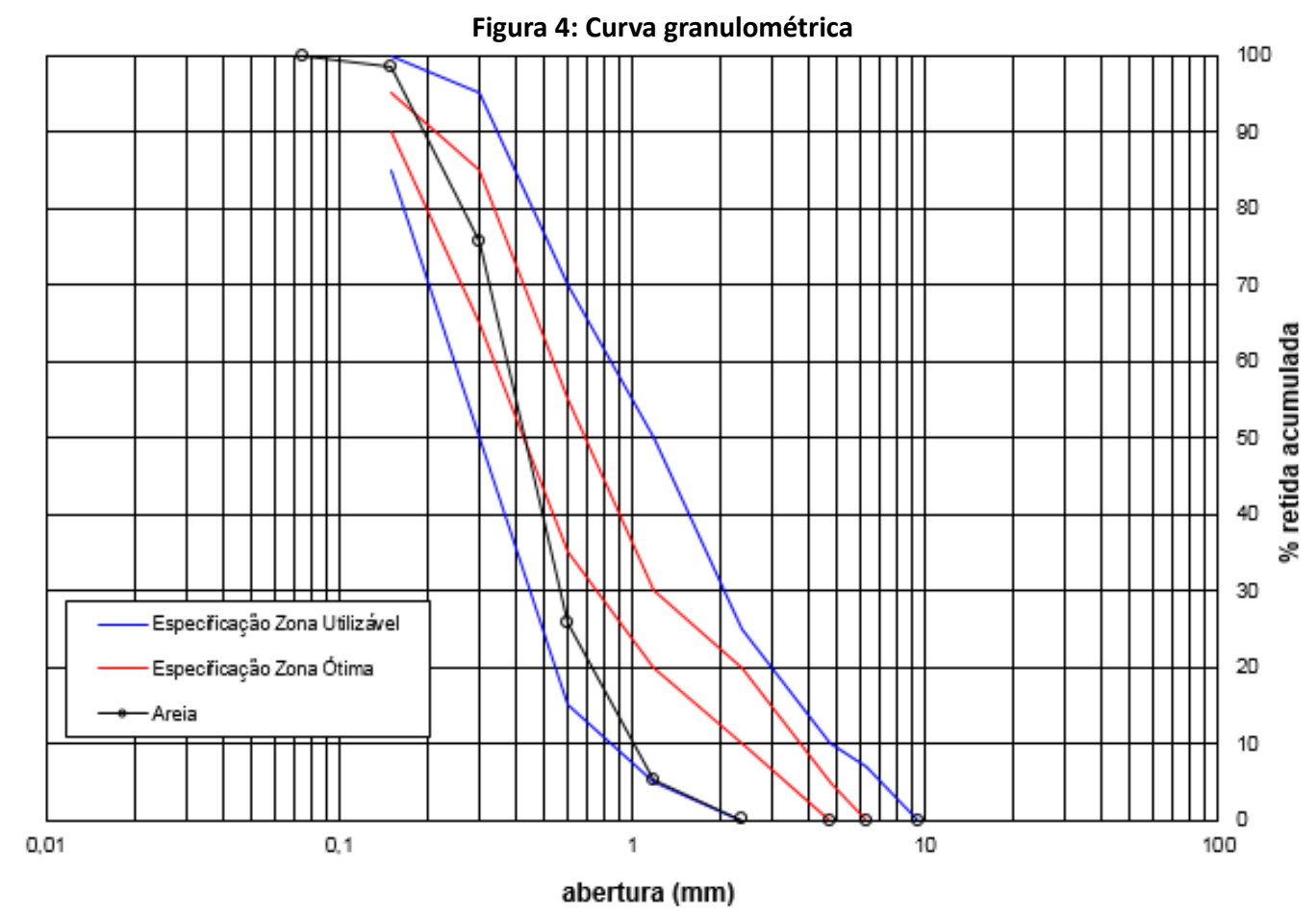

Fonte: Próprio autor.

\subsection{Resultados dos ensaios}

Tabela 2: Consistência das argamassas

\begin{tabular}{lcc}
\hline Identificação das Argamassas & $\begin{array}{c}\text { Abertura média } \\
\text { (cm) }\end{array}$ & Desvio Padrão \\
\hline CME 0\% & 31,17 & $\pm 0,29$ \\
CME 10\% & 29,17 & $\pm 0,29$ \\
CME 20\% & 27,17 & $\pm 0,76$ \\
CME 30\% & 25,17 & $\pm 0,29$ \\
CME 40\% & 24,33 & $\pm 0,58$ \\
CME 50\% & 21,67 & $\pm 0,29$ \\
\hline
\end{tabular}

Fonte: Próprio autor. 


\section{ANAP Brasil \\ ISSN 1984-3240 \\ V. 10 , n. 18}

\section{REVISTA C IENTÍF I CA 2017}

O ensaio de consistência mostra que conforme acrescenta-se a $\mathrm{CME}$, há uma diminuição da fluidez das argamassas, fato esta que já era esperado, uma vez que a inserção de um material fino tente decrementar as propriedades notórias das argamassas frescas, a exemplo da fluidez e da trabalhabilidade. Esta última foi observada durante a moldagem dos corpos-de-prova, principalmente para os traços $\mathrm{CME} 40 \%$ e $\mathrm{CME} 50 \%$, em que houve uma notória queda da plasticidade da mistura.

A tabela 3 fornece os dados das rupturas das argamassas, aos sete dias, ensaiadas à compressão axial.

Tabela 3: Resistência à compressão aos 7 dias

\begin{tabular}{lcc}
\hline Identificação das Argamassas & $\begin{array}{c}\text { Resistência à } \\
\text { Compressão } \\
\text { Média (MPa) }\end{array}$ & Desvio Padrão \\
\hline CME 0\% & 39,38 & $\pm 1,54$ \\
CME 10\% & 44,14 & $\pm 1,51$ \\
CME 20\% & 43,78 & $\pm 1,48$ \\
CME 30\% & 46,41 & $\pm 1,55$ \\
CME 40\% & 40,66 & $\pm 2,44$ \\
CME 50\% & 39,52 & $\pm 1,42$ \\
\hline
\end{tabular}

Fonte: Próprio autor.

A figura 5 ilustra a dispersão dos valores de resistência. De maneira geral, as barras à esquerda trazem o valor mínimo encontrado para as resistências, enquanto que a barra da direita fornece os valores máximos. 


\section{ANAP Brasil \\ ISSN 1984-3240 \\ v. 10, n. 18}

\section{REVISTA C IENTÍFICA 2017}

Figura 5: Valores máximos e mínimos das resistências à compressão das argamassas

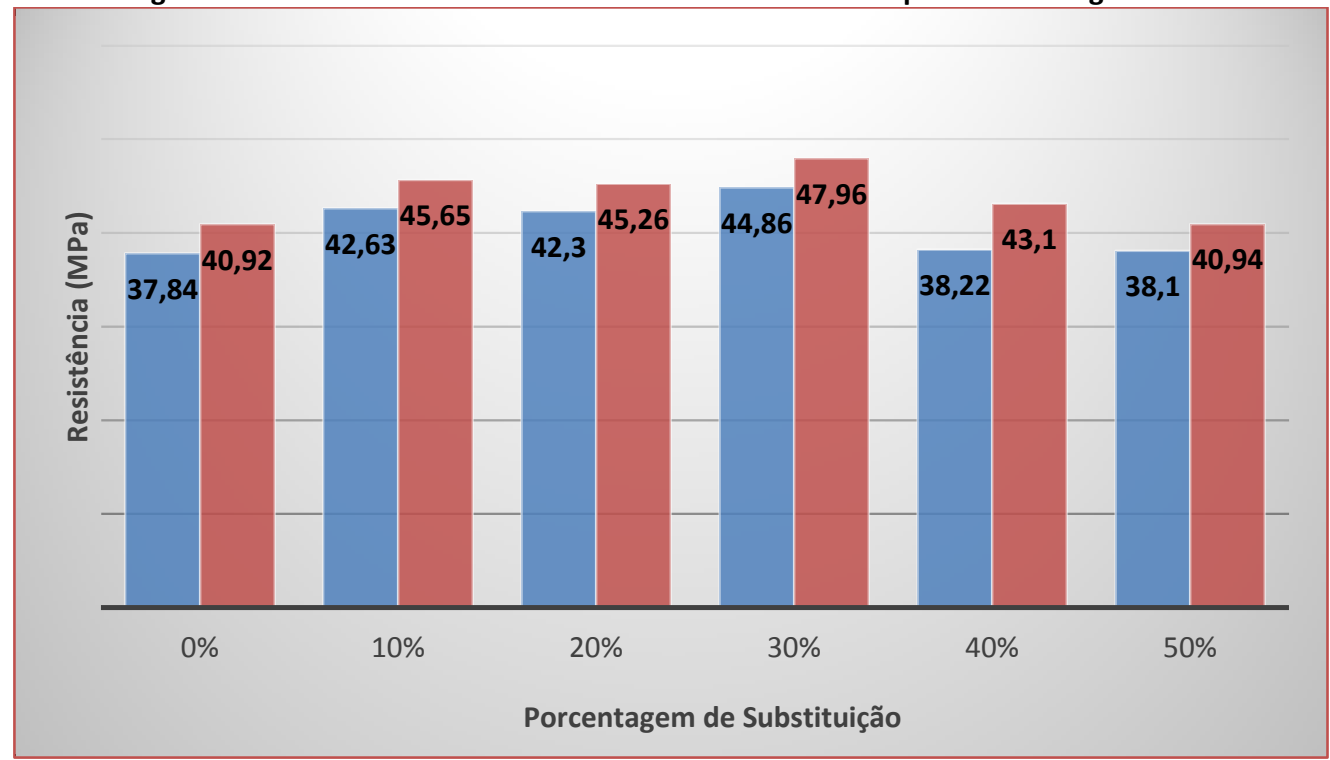

Fonte: Próprio autor.

A tabela 4 fornece os dados do ensaio de absorção de água das argamassas.

Tabela 4: Absorção de água aos 7 dias

\begin{tabular}{lcc}
\hline Identificação das Argamassas & Absorção de água (\%) & Desvio Padrão \\
\hline CME 0\% & 0,1817 & $\pm 0,1094$ \\
CME 10\% & 0,3777 & $\pm 0,1984$ \\
CME 20\% & 0,2244 & $\pm 0,0685$ \\
CME 30\% & 0,0509 & $\pm 0,1231$ \\
CME 40\% & 0,1070 & $\pm 0,0210$ \\
CME 50\% & 0,1182 & $\pm 0,0025$ \\
\hline
\end{tabular}

Fonte: Próprio autor.

Em termos gerais, a aplicação da cinza como substituição parcial ao agregado miúdo trouxe resultados favoráveis aos elaboradores dos trabalho. De certa forma, o número de amostras é de extrema relevância no estudo das propriedades dos concretos e argamassas endurecidos. Uma vez que a amostragem utilizada foi de quatro corpos-de-prova por traço elaborado, e considerando o desvio gerado pelas resistências à compressão médias, não se pode afirmar veemente que as substituições apresentaram de fato resultados mais favoráveis com relação à amostra controle (CME 0\%). Contudo, observa-se que para todas as substituições que foram instrumento de estudo, houve incremento na resistência. A leitura dos desvios confirma o que foi mencionado anteriormente, pois existe uma amplitude notória das médias de resistência, apesar de mesmo considerando esse intervalo de valores, os resultados permanecem favoráveis. Por exemplo, tomando-se com referência a traço CME 30\%, a resistência de 46,41 


\section{ANAP Brasil \\ ISSN 1984-3240 \\ v. 10, n. 18}

\section{REVISTA C IENTÍFICA $\quad 2017$}

MPa com o desvio de $\pm 1,55$ resulta nos extremos de 44,86 MPa e 47,96 $\mathrm{MPa}$, ou seja, valores acima do que foi obtido no CME $0 \%$.

A absorção de água foi um parâmetro mais aberto nos resultados, visto que o dado que apresentou melhor teor de absorção foi o CME 30\% (0,0509\% de água absorvida), incluindo a traço controle CME $0 \%$. Entretanto, os traços com menor desvio padrão foram o CME $40 \%$ e o CME 50\%, definidos em 0,0209 e 0,0025 respectivamente. Os menores teores foram garantidos a partir de substituições acima de $30 \%$, com destaque para $40 \%$ e $50 \%$.

De certa forma, os resultados das tabelas 3 e 4 solidificam a viabilidade da CME aplicada as argamassas de cimento. Inclusive, existe a possibilidade de substituir a areia da mistura em porcentagens maiores que $50 \%$ e verificar as dados apresentados. Portanto, considerando a disponibilidade da areia, um novo agregado plausível pode ser estudado com mais ênfase, não somente nas argamassas, mas em todas as matrizes cimentícias. Considerando a sistemática do manuseio de resíduos, é possível utilizar os descartes das indústrias de papel e celulose dentro da construção civil.

\section{CONCLUSÃO}

Com base nos resultados obtidos na tabela 3, pode-se concluir que substituindo $30 \%$ da areia por $\mathrm{CME}$, obteve-se resultados satisfatórios quanto a resistência à compressão das argamassas, nos traços acima deste teor de substituição a resistência começa a diminuir.

Em relação ao ensaio de consistência conforme aumenta-se o teor de $\mathrm{CME}$, há uma notória queda na fluidez e trabalhabilidade das argamassas. Para o traço com $10 \%$ de $\mathrm{CME}$, conseguiuse uma maior plasticidade nas argamassas, em relação as outras amostras utilizando CME. Utilizando o traço com 40 e 50\% de CME, houve uma queda considerável na consistência, tornando-se a argamassa menos fluida e plástica.

Na questão de absorção de água, os maiores teores de absorção de água foram estabelecidos aos traços com porcentagens acima de 30\% de CME. O traço com 30\% de CME apresentou-se $0,0509 \%$ de água absorvida. Todavia esse traço com 30\% de CME obteve um desvio padrão considerável. No traço com 40 e 50\% de $\mathrm{CME}$, apresentou-se um menor desvio padrão em relação ao traço com 30\% de CME, definidos em 0,0209 e 0,0025, nesta ordem.

Considerando os resultados obtidos das tabelas 3 e 4, a viabilidade da aplicação do CME em argamassas de cimento é evidenciada. Inclusive, existe a possibilidade de substituir a areia da mistura em porcentagens maiores que $50 \%$ e verificar os dados apresentados. Portanto, considerando a disponibilidade da areia, um novo agregado plausível pode ser estudado com mais ênfase, não somente nas argamassas, mas em todas as matrizes cimentícias. E com relação a sistemática do manuseio de resíduos, é possível utilizar os descartes das indústrias de papel e celulose dentro da construção civil. 


\section{ANAP Brasil \\ ISSN 1984-3240 \\ v. 10, n. 18}

\section{REVISTA C IENTÍFICA 2017}

\section{REFERÊNCIAS BIBLIOGRÁFICAS}

A.M.NEVILLE. Propriedades do concreto. 5. ed. Porto Alegre: Bookman, 2016. 912 p.

ASSOCIAÇÃO BRASILEIRA DE NORMAS TÉCNICAS - ABNT. NBR 13276: Argamassa para Assentamento e Revestimento de Paredes e Tetos - Preparo da mistura e determinação do índice de consistência. Rio de Janeiro: ABNT, 2016.

ASSOCIAÇÃO BRASILEIRA DE NORMAS TÉCNICAS - ABNT. NBR 5739: concreto - ensaio de compressão de corpos-deprova cilíndricos concreto. Rio de Janeiro, 2007. 9 p.

ASSOCIAÇÃO BRASILEIRA DE NORMAS TÉCNICAS - ABNT. NBR 9778: argamassa e concreto endurecidos determinação da absorção de água, índice de vazios e massa específica. Rio de Janeiro, 2009. 4 p.

ASSOCIAÇÃO BRASILEIRA DE NORMAS TÉCNICAS - ABNT. NBRNM 248: agregados - determinação da composição granulométrica. Rio de Janeiro, 2001. 6 p.

ASSOCIAÇÃO BRASILEIRA DE NORMAS TÉCNICAS - ABNT. NBRNM 30: agregado miúdo - determinação da absorção de água. Rio de Janeiro, 2001. 3 p.

ASSOCIAÇÃO BRASILEIRA DE NORMAS TÉCNICAS - ABNT. NBRNM 45: agregados - determinação da massa unitária, massa unitária compactada e seca e do volume de vazios. Rio de Janeiro, 2006. 8 p.

ASSOCIAÇÃO BRASILEIRA DE NORMAS TÉCNICAS - ABNT. NBRNM 52: agregado miúdo - determinação de massa específica e massa específica aparente. Rio de Janeiro, 2009. 6 p.

ASSOCIAÇÃO BRASILEIRA DE NORMAS TÉCNICAS - ABNT. NBRNM 53: agregado graúdo - determinação de massa específica, massa específica aparente e absorção de água. Rio de Janeiro, 2009. 8 p.

CMPC Celulose Riograndense. 2017. Disponível em: http://www.celuloseriograndense.com.br/produtos. Acesso em 12 set. 2017.

FAIRBAIRN, Eduardo M.r. et al. Cement replacement by sugar cane bagasse ash: $\mathrm{CO} 2$ emissions reduction and potential for carbon credits. Journal Of Environmental Management, [s.l.], v. 91, n. 9, p.1864-1871, set. 2010. Elsevier BV. http://dx.doi.org/10.1016/j.jenvman.2010.04.008.

FOELKEL, Celso. Resíduos Sólidos Industriais do Processo de Fabricação de Celulose Kraft de Eucalipto: Resíduos Minerais. Eucalyptus Online Book. São Paulo, v. 25, n. 5, out. 2008. Disponível em: < http://www.eucalyptus.com.br/capitulos/PT06_fibras_refugos.pdf >. Acesso em 12 set. 2017.

FOELKEL, Celso. Resíduos Sólidos Industriais do Processo de Fabricação de Celulose Kraft de Eucalipto: Resíduos Minerais. Eucalyptus Online Book. São Paulo, v. 25, n. 5, out. 2011. Disponível em: < http://www.eucalyptus.com.br/eucaliptos/PT25_ResiduosMinerais.pdf>. Acesso em 12 set. 2017.

KIHARA, Yushiro; CENTURIONE, Sérgio Luiz. O Cimento Portland. In: ISAIA, Geraldo Cechella. Concreto Ensino, Pesquisa e Realizações. São Paulo: Isipis, 2005. Cap. 10. p. 295-322.

ROSSI, T. et al. Waste from eucalyptus wood steaming as a natural dye source for textile fibers. Journal Of Cleaner Production, [s.I.], v. 143, p.303-310, fev. 2017. Elsevier BV.

SANTOS, Sónia A.o. et al. Secondary metabolites from Eucalyptus grandis wood cultivated in Portugal, Brazil and South Africa. Industrial Crops And Products, [s.I.], v. 95, p.357-364, jan. 2017. Elsevier BV. 